\title{
Quantification of plasma exosome is a potential prognostic marker for esophageal squamous cell carcinoma
}

\author{
YASUNORI MATSUMOTO, MASAYUKI KANO, YASUNORI AKUTSU, NAOYUKI HANARI, \\ ISAMU HOSHINO, KENTARO MURAKAMI, AKIHIRO USUI, HIROSHI SUITO, \\ MASAHIKO TAKAHASHI, RYOTA OTSUKA, HU XIN, AKI KOMATSU, \\ KEIKO IIDA and HISAHIRO MATSUBARA
}

Department of Frontier Surgery, Chiba University Graduate School of Medicine, Chiba 260-8670, Japan

Received March 7, 2016; Accepted July 25, 2016

DOI: $10.3892 / o r .2016 .5066$

\begin{abstract}
Exosomes play important roles in cancer progression. Although its contents (e.g., proteins and microRNAs) have been focused on in cancer research, particularly as potential diagnostic markers, the exosome behavior and methods for exosome quantification remain unclear. In the present study, we analyzed the tumor-derived exosome behavior and assessed the quantification of exosomes in patient plasma as a biomarker for esophageal squamous cell carcinoma (ESCC). A CD63-GFP expressing human ESCC cell line (TE2-CD63-GFP) was made by transfection, and mouse subcutaneous tumor models were established. Fluorescence imaging was performed on tumors and plasma exosomes harvested from mice. GFP-positive small vesicles were confirmed in the plasma obtained from TE2-CD63-GFP tumor-bearing mice. Patient plasma was collected in Chiba University Hospital $(\mathrm{n}=86)$. Exosomes were extracted from $100 \mu 1$ of the plasma and quantified by acetylcholinesterase (AChE) activity. The relationship between exosome quantification and the patient clinical characteristics was assessed. The quantification of exosomes isolated from the patient plasma revealed that esophageal cancer patients $(n=66)$ expressed higher exosome levels than non-malignant patients $(n=20)$ $(\mathrm{P}=0.0002)$. Although there was no correlation between the tumor progression and the exosome levels, exosome number was the independent prognostic marker and low levels of exosome predicted a poor prognosis $(\mathrm{P}=0.03)$. In conclusion, exosome levels may be useful as an independent prognostic factor for ESCC patients.
\end{abstract}

Correspondence to: Dr Masayuki Kano, Department of Frontier Surgery, Chiba University Graduate School of Medicine, 1-8-1 Inohana, Chuo-Ku, Chiba-Shi, Chiba 260-8670, Japan

E-mail:mkano@chiba-u.jp

Key words: esophageal squamous cell carcinoma, exosome, quantification, prognostic factor, biomarker

\section{Introduction}

Esophageal cancer is the sixth leading cause of cancer-related death, and in 2013, it was estimated that 442,000 new cases were diagnosed with 440,000 deaths due to the disease worldwide, and the overall 5-year survival ranges from 15 to $25 \%$ (1-3). Esophageal squamous cell carcinoma (ESCC) is one of the major histological types of esophageal cancer, particularly in the 'Asian Esophageal Cancer Belt', which extends from Middle East countries to Eastern Asia, including Japan and is highly aggressive due to its tendency to metastasize to the lymph nodes and organs $(4,5)$. To improve the poor prognosis, it is necessary to reveal the mechanism of cancer progression and detect prognostic biomarkers for the prognosis.

Exosomes are small membrane vesicles secreted from most cell types. They contain proteins, lipids and nucleic acids (e.g., mRNA and miRNA) and are thought to have some function, particularly in signal transduction $(6,7)$. Our laboratory previously reported that exosomes from the serum and proximal lymph nodes of patients with ESCC contained high miR-1246 levels (8). Thus, some information may be delivered to the proximal lymph node via the exosome. Indeed, in the field of cancer research, tumor-released exosomes have been reported to influence tumor progression (9), resistance to chemotherapy (10) or immune evasion $(11,12)$. Exosomes released from the bone marrow or cancer-associated fibroblasts (CAFs) also correlate with chemoresistance (13) or tumor dormancy $(14,15)$. Although exosome contents isolated from the patients peripheral blood were reported to be useful as a diagnostic or prognostic factor for cancers (16), it is difficult to distinguish whether exosomes originate from the tumor itself or as a result of the host response against the tumor. Moreover, no precise quantification method for exosomes has to date been developed.

In the present study, we report on the behavior of tumorderived exosomes in a mouse model with fluorescence imaging and determine the relationship between the quantification of plasma exosomes, measured by the acetylcholinesterase (AChE) activity, which is known to be elevated within the exosome $(17,18)$, and the clinical characteristics in human $\operatorname{ESCC}(19,20)$. 


\section{Materials and methods}

Cell culture. TE2 human ESCC cell line and SCCVII murine SCC cell line were used in the present study. TE2 cell line was obtained from Cell Resource Center for Biomedical Research Institute of Development, Aging and Cancer, Tohoku University (Sendai, Japan). SCCVII cell line was kindly provided by Professor Yuta Shibamoto (Department of Quantum Radiology, Nagoya City University, Nagoya, Japan).

The cells were cultured in Dulbecco's modified Eagle's medium (DMEM) (Life Technologies, Grand Island, NY, USA) supplemented with $10 \%$ fetal bovine serum (FBS), $100 \mathrm{U} / \mathrm{ml}$ penicillin sodium and $100 \mu \mathrm{g} / \mathrm{ml}$ streptomycin in a humidified atmosphere containing $5 \% \mathrm{CO}_{2}$ at $37^{\circ} \mathrm{C}$.

CD63-GFP expressing cells. A CD63-GFP fusion protein expression vector (CYTO120-VA1; System Biosciences, Mountain View, CA, USA) was used to transfect TE2 cells. After selection by puromycin-containing medium and the limiting dilution technique, a single cell-derived cell line, CD63-GFP stably expressing TE2 (TE2-CD63-GFP), was established.

Extraction of exosomes from culture media of ESCC cell line. Exosomes were isolated from culture media using an isolation reagent (Exosome Isolation kit from culture media; Invitrogen, Carlsbad, CA, USA) according to the manufacturer's protocol. The cells were seeded onto $10 \mathrm{~cm}$ dishes at a concentration of $1 \times 10^{6}$ cells/dish with DMEM containing $10 \%$ of exosome-free FBS (System Biosciences). After a 48-h incubation, conditioned media were harvested for exosome extraction. The culture medium was centrifuged at 2,000 x g for $30 \mathrm{~min}$ to remove cells and debris. Then, these supernatants were passed through a $220 \mathrm{~nm}$ filter and were transferred to new tubes, and the reagents were added. After incubation, the samples were centrifuged at $10,000 \mathrm{x}$ g for $1 \mathrm{~h}$ and the supernatants were discarded. The exosomes were pelleted at the bottom of the tubes and the pellets were resuspended in phosphate-buffered saline (PBS) for fluorescence imaging.

Animal care and mouse model of human ESCC. Six-week-old female nude mice (BALB/c Slc-nu/nu) were used for the present study. The 8 mice were divided into two groups. TE2 ( $1 \times 10^{7}$ cells in $\left.50 \mu \mathrm{l} \mathrm{PBS}\right)$ were injected subcutaneously (s.c.) into the backs of mice in one group ( $n=4)$, and the same amount of TE2-CD63-GFP cells were injected s.c. into the mice in another group $(n=4)$. Eight weeks after injection, the mice were sacrificed and the tumor and plasma were harvested. The exosomes were isolated from plasma, and used for fluorescence imaging and quantification as hereinafter described.

The tumors were assessed with hematoxylin and eosin (H\&E) stain, immunohistochemistry (IHC) staining of CD63, and fluorescence imaging. Anti-human CD63 rabbit polyclonal antibody (cat. \#15363; Santa Cruz Biotechnology, Inc., Dallas, TX, USA) was used as a primary antibody for IHC staining.

Six-week-old female $\mathrm{C} 3 \mathrm{H} / \mathrm{He}$ mice were used to assess the exosome amount within the early and advanced cancer models. SCCVII $\left(5 \times 10^{5}\right.$ cells in $50 \mu 1$ PBS $)$ were injected s.c. into the backs of mice. The plasma were harvested 1 or 6 weeks after injection from each 4 mice as the models for early and advanced cancer. The plasma were also harvested from 4 mice without tumor, and each plasma was used for exosome isolation and quantification as hereinafter described. The tumor volume in $\mathrm{mm}^{3}$ was calculated by the formula: Volume $=(\text { width })^{2} \mathrm{x}$ length $/ 2$.

The present study was performed according to the guidelines on animal experiments, and approved by the animal experiment and welfare committee at Chiba University.

Patient samples. The plasma samples were collected from histologically proven ESCC patients at their first visit to Chiba University Hospital (Chiba, Japan) between December 2011 to December 2012. Patients with active malignancy in any other organ were excluded, and none of the patients had been treated at the time of sample collection. A total of 66 samples from cancer patients were collected, and 20 samples from patients with no malignancy (e.g., esophageal achalasia and reflux esophagitis) were collected during the same period.

The clinical data including blood testing and clinical characteristics of the cancer were obtained from the clinical database. The neutrophil to lymphocyte ratio (NLR) was calculated as neutrophils/lymphocytes (21). The Glasgow Prognostic Score (GPS) was calculated according to the cut-off values of $1.0 \mathrm{mg} / \mathrm{dl}$ for C-reactive protein and $3.5 \mathrm{~g} / \mathrm{dl}$ for albumin, as previously reported (22). The staging classification was confirmed by the classification of the Union for International Cancer Control (UICC) TNM staging system 7th edition. The present study was approved by the Ethics Committee of Graduate School of Medicine, Chiba University. A written informed consent was obtained from all the patients.

Extraction of exosomes from the plasma. Each plasma sample was centrifuged at $2,000 \mathrm{x}$ g for $20 \mathrm{~min}$ at room temperature to remove cells and debris. The supernatant containing the partially clarified plasma was transferred to a new tube, and then centrifuged at $10,000 \mathrm{x}$ g for $20 \mathrm{~min}$ at room temperature to remove debris. Then, the supernatant containing the clarified plasma was transferred to a new tube, $100 \mu \mathrm{l}$ of plasma was transferred to a new tube and exosomes were isolated using an exosome isolation reagent (Total Exosome Isolation kit from plasma; Invitrogen) according to the manufacturer's protocol.

Exosome quantification. Each obtained exosome preparation from culture media or plasma was dissolved in $100 \mu$ l of PBS and quantified according to the AChE activity (EXOCET Exosome Quantification kit; System Biosciences) according to the manufacturer's protocol. To confirm the reliability of this protocol, differing concentrations of exosome were isolated from 50,100 and $200 \mu \mathrm{l}$ plasma, collected from healthy controls and quantified. In addition, $10 \mathrm{ESCC}$ patients samples were quantified using both $\mathrm{AChE}$ activity and nanoparticle tracking analysis, and the correlation was assessed. Nanoparticle tracking analysis was kindly performed by Mr. Rii Morimura (Toppan Printing, Japan) using NanoSight NS500 (Malvern Instruments, Malvern, UK).

Fluorescence imaging. The fluorescent and bright field images of the mouse tumor tissue sections and isolated exosomes were acquired using an Axio Observer Z1 microscope and an AxioCam MRm camera (Carl Zeiss, Oberkochen, Germany). 
Electron microscope. The exosome sample was absorbed to formvar film coated copper grids (400 mesh) and was stained with $2 \%$ phosphotungstic acid solution ( $\mathrm{pH} 7.0)$ for $30 \mathrm{sec}$. The sample was observed by a transmission electron microscope (JEM-1400Plus; JEOL Ltd., Tokyo, Japan) at an acceleration voltage of $80 \mathrm{kV}$. Digital images were captured by a CCD camera (Veleta; Olympus Soft Imaging Solutions $\mathrm{GmbH}$, Münster, Germany).

Statistical analysis. Data of the exosome number are expressed as the average \pm SD (standard deviation). Differences in the relationships between the number of exosomes and categorical clinicopathological features were assessed using the Mann-Whitney U test or Student's t-test. Comparisons among more than two groups were assessed using a one-way factorial ANOVA and the Kruskal-Wallis test. The Kaplan-Meier method was used for the survival analysis and the log-rank test was used to determine the statistical significance of the difference between the two groups. Prognostic factors were determined by univariate and multivariate analyses (Cox proportional hazard regression model). Statistical significance was considered to exist at P-values $<0.05$. All data were statistically analyzed using JMP version 12 (SAS Institute Inc., Cary, NC, USA).

\section{Results}

CD63-GFP expressing cells release GFP-tagged exosomes. Stable CD63-GFP expressing TE2 (TE-CD63-GFP) cells were established as described above (Fig. 1A and B). The exosomes were isolated from the culture medium of TE2-CD63-GFP and TE2 cells using an exosome isolation kit. The exosomes were imaged by electron microscope and fluorescence. The small round particles, some $50 \mathrm{~nm}$ in diameter, were recognized and the presence of GFP-positive, but RFP-negative, small vesicles were confirmed only in exosome isolated from TE2-CD63-GFP (Fig. 1C and D).

Tumor-derived exosomes are released outside the tumor and circulated in the blood flow. Subcutaneous tumors comprising TE2-CD63-GFP or TE2 cells were successfully formed following s.c. injection in each 4 mice. Eight weeks after s.c. injection of the cells, the tumor and blood samples were harvested. There was no difference between the two groups in the appearance of H\&E stain and IHC staining of CD63 (Fig. 2A).

Fluorescent imaging with GFP revealed intracellular foci existed mainly in the cytoplasm among the TE2-CD63-GFP tumor, and the appearance was similar to that of cultured cells (Fig. 2A and B). In addition, the presence of GFP-positive, but RFP-negative, small vesicles were confirmed in isolated exosomes from the plasma of TE2-CD63-GFP tumor-bearing mice (3/4), but no GFP-positive particle was confirmed in the group of TE2 tumor (0/4) (Fig. 2C).

Exosome can be quantified by AChE activity. The number of exosomes isolated from 50, 100 and $200 \mu \mathrm{l}$ of plasma from healthy controls was $63.9 \pm 51.2\left(\times 10^{7}\right), 145.2 \pm 33.2\left(\times 10^{7}\right)$ and

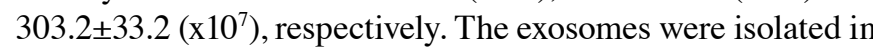
a dose-dependent manner $\left(\mathrm{R}^{2}=0.99 ; \mathrm{P}=0.044\right.$; Fig. $\left.3 \mathrm{~A}\right)$. There were positive correlation between the exosome number quantified by AChE activity and nanoparticle tracking analysis $\left(\mathrm{R}^{2}=0.44, \mathrm{P}=0.036\right.$; Fig. 3B $)$.

The quantification of plasma exosome isolates from murine SCC models. The group of nude mice (BALB/c Slc-nu-nu) with subcutaneous tumor composed of TE2-CD63-GFP (tumor volume, $1042 \pm 293 \mathrm{~mm}^{3}$ ) had higher amount of plasma exosome $\left(1290 \pm 186 \times 10^{8} / \mathrm{ml}\right)$ than the group of mice without tumor $\left(1007 \pm 162 \times 10^{8} / \mathrm{ml}\right)(\mathrm{P}=0.048$; t-test; Fig. 4A).

Concerning the $\mathrm{C} 3 \mathrm{H} / \mathrm{He}$ mouse groups, the exosome amounts were $911 \pm 382 \times 10^{8} / \mathrm{ml}$ in the group without tumor, $979 \pm 194 \times 10^{8} / \mathrm{ml}$ in the group with early cancer (1 week after injection), $695 \pm 170 \times 10^{8} / \mathrm{ml}$ in the group with advanced cancer (6 weeks after injection). There was a significant difference in the exosome number between the groups of early and advanced cancer $(\mathrm{P}=0.043$; t-test; Fig. $4 \mathrm{~B})$. The tumor volume was $1.2 \pm 1.2 \mathrm{~mm}^{3}$ in the mice 1 week after injection, $2712 \pm 1339 \mathrm{~mm}^{3}$ in the mice 6 weeks after injection, and there was no correlation between the tumor volume and the exosome number.

Exosome quantification in patient plasma is higher in cancer patients. The quantification of exosomes isolated from $100 \mu \mathrm{l}$ of the patients plasma was similarly measured. The clinical characteristics of the patients are shown in Table I. The median number of plasma exosomes was $493.9 \times 10^{8} / \mathrm{ml}$ in esophageal cancer patients and $325.9 \times 10^{8} / \mathrm{ml}$ in non-malignant patients $(\mathrm{P}=0.0002$; Mann-Whitney U test; Fig. 5A). There was no relationship between the exosome amount and several factors, such as the white blood cell count (WBC), hemoglobin (Hb), total protein (TP), albumin, C-reactive protein (CRP), CEA, CYFRA, SCC-Ag level, as well as $\mathrm{NLR}\left(\mathrm{R}^{2}=0.014,0.006\right.$, $0.123,0.055,0.014,0.009,0.003,0.01$ and 0.02 , respectively). Furthermore, there was also no difference in exosome amount within the groups of GPS score 0,1 and 2.

The exosome amount did not correlate with the tumor progression. The number of exosomes and tumor characteristics were then assessed. Regarding the tumor depth, the number of exosomes was $565.1 \pm 210.6$ in $\mathrm{T} 1,451.0 \pm 149.0$ in $\mathrm{T} 2,627.7 \pm 283.0$ in $\mathrm{T} 3$, and $510.8 \pm 340.2$ in $\mathrm{T} 4$ with median values of $508.0,428.9,564.6$ and $425.2\left(\times 10^{8} / \mathrm{ml}\right)$, respectively (Fig. 5B). There was no significant difference between the groups $(\mathrm{P}=0.45$; ANOVA). In relation to the lymph node status, the number of exosomes was $585.9 \pm 237.6$ in $\mathrm{N} 0,481.6 \pm 202.0$ in $\mathrm{N} 1,632.4 \pm 331.4$ in $\mathrm{N} 2$ and $492.7 \pm 288.5$ in N3 with median values of 482.4, 462.1, 598.9 and 440.5 $\left(\mathrm{x} 10^{8} / \mathrm{ml}\right)$, respectively (Fig. 5C; $\mathrm{P}=0.34$; ANOVA). The number of exosomes was $585.9 \pm 237.6$ in the negative lymph node metastasis group and $549.3 \pm 292.7$ in the positive group with median values of 482.4 and $505.4\left(\times 10^{8} / \mathrm{ml}\right)$, respectively ( $\mathrm{P}=0.48$; Mann-Whitney $\mathrm{U}$ test). Regarding the distant metastatic status, the number of exosomes was 568.1 \pm 280.6 in M0 and 433.9 \pm 187.2 in M1 with median values of 482.0 and 516.4 (x10\% $/ \mathrm{ml}$ ), respectively (Fig. 5D; $\mathrm{P}=0.54$; Mann-Whitney U test). Regarding the tumor stage, the number of exosomes was $563.0 \pm 221.8$ in stage I, $676.9 \pm 252.0$ in stage II, 559.4 \pm 3090.1 in stage III, and $433.9 \pm 187.2$ in stage IV, with median values of 482.0, 640.1, 464.2 and 516.4 (x10\% $/ \mathrm{ml})$, respectively (Fig. 5E). 
A

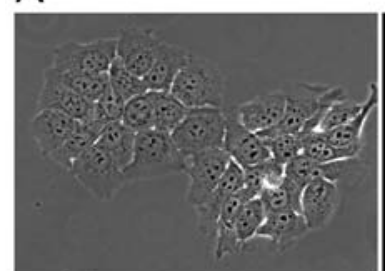

Bright Field (BF)

C

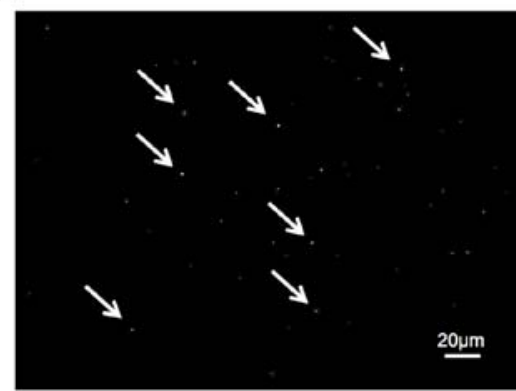

GFP

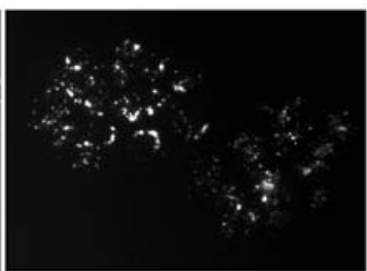

GFP

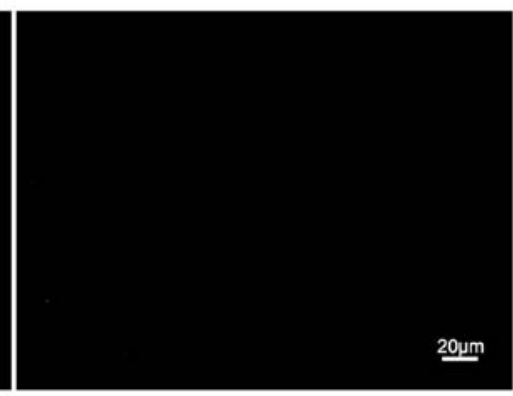

RFP

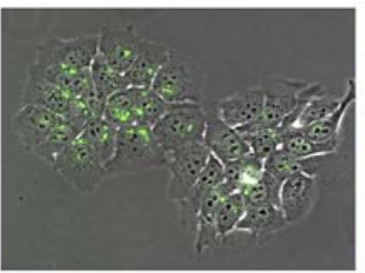

Merge

B

D

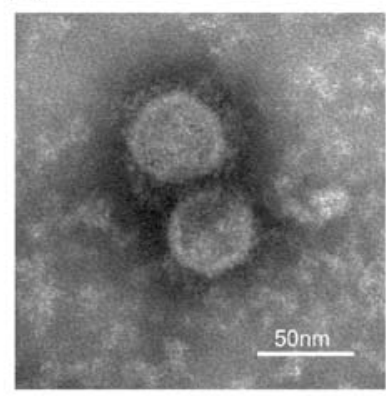

GFP + DAPI

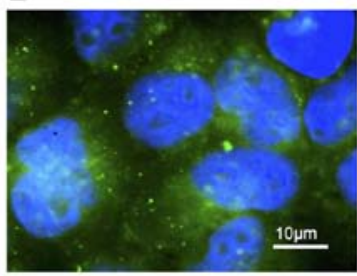

Figure 1. (A) A stable TE2 cell line expressing CD63-GFP (TE2-CD63-GFP) was established by transduction with a CD63-GFP expression vector. Left, bright-field (BF); middle, GFP; right, merge (BF + GFP). (B) The enlarged fluorescence image of TE2-CD63-GFP cells. GFP-expressing foci were confirmed in the cytoplasm and the matrix of the cells (GFP + DAPI, bar, $10 \mu \mathrm{m}$ ). (C) GFP and RFP images of isolated exosome from TE2-CD63-GFP culture medium. GFP positive, but RFP negative, small foci were confirmed (bar, $20 \mu \mathrm{m}$ ). (D) An electron microscope image of exosome isolated from TE2-CD63-GFP culture medium. Small round particles, some $50 \mathrm{~nm}$ in diameter were confirmed (bar, $50 \mathrm{~nm}$ ).

A

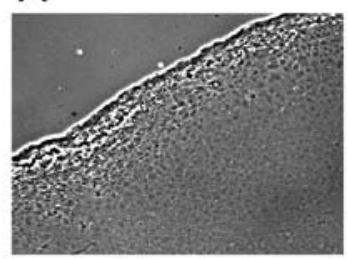

BF

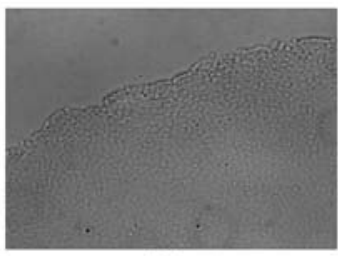

BF

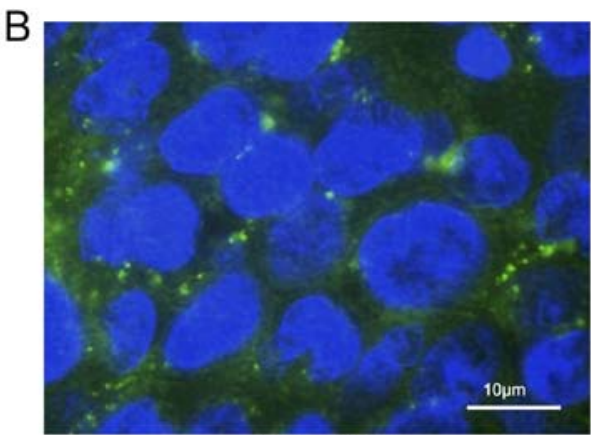

GFP + DAPI
TE2 CD63-GFP

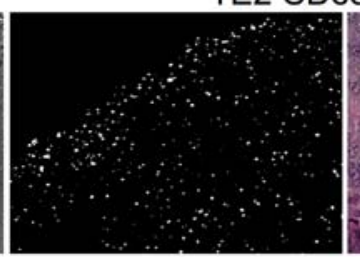

GFP

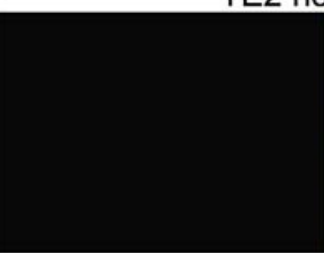

GFP

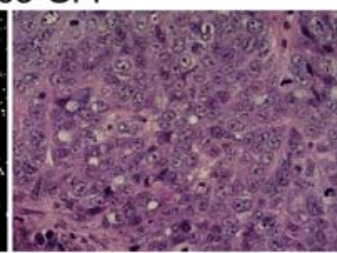

$H \& E(x 400)$

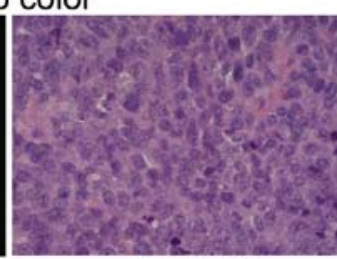

$H \& E(x 400)$

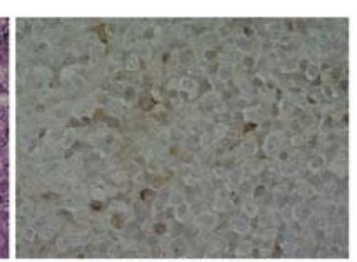

CD63 (x400)

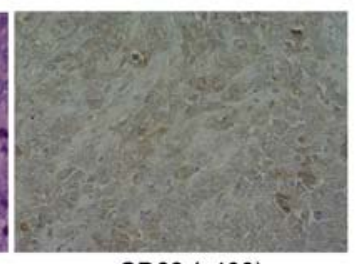

CD63 (x400)

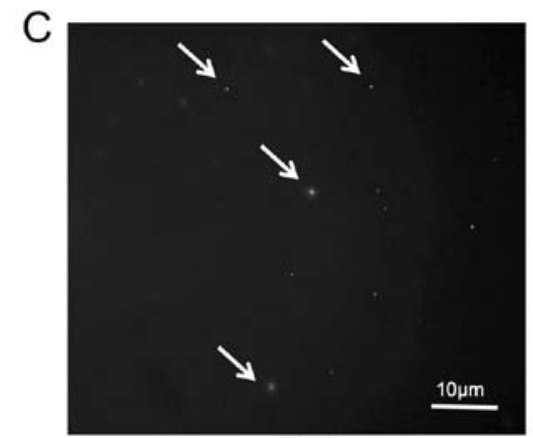

GFP

Figure 2. (A) Representative images of subcutaneous tumor composed of TE2-CD63-GFP and TE2 cells [bright-field (BF), GFP fluorescence, H\&E stain, immunohistochemistry (IHC) staining of CD63]. Each tumor was established by a subcutaneous injection of 1x107 cells of TE2-CD63-GFP or TE2. Eight weeks after injection, the tumors were harvested and imaged. The tumors had similar appearance in H\&E stain and IHC stain of CD63, but only TE2-CD63-GFP tumor had GFP-positive foci in the tumor. (B) The enlarged image of TE2-CD63-GFP tumor. GFP expressing foci were confirmed mainly in cytoplasm as well as the cultured TE2-CD63-GFP cells (bar, $20 \mu \mathrm{m}$ ). (C) A representative GFP image of isolated exosomes from mouse plasma bearing a TE2-CD63-GFP tumor. GFP-positive, but RFP-negative, small foci were confirmed (bar, $10 \mu \mathrm{m}$ ). 
A

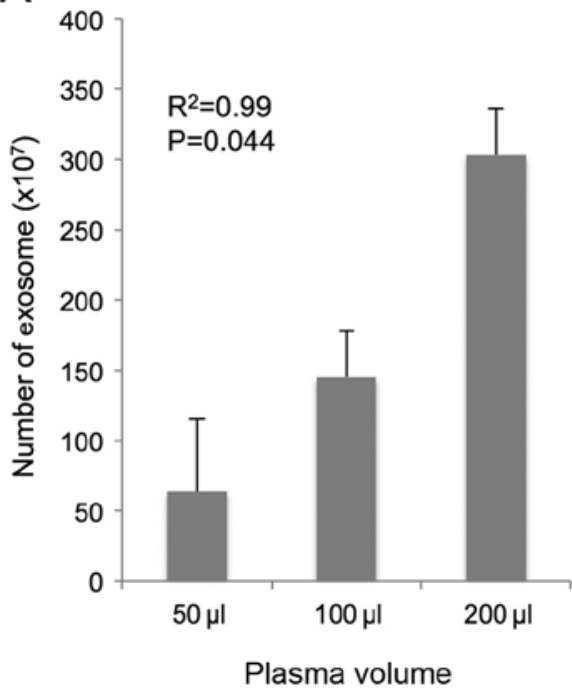

B

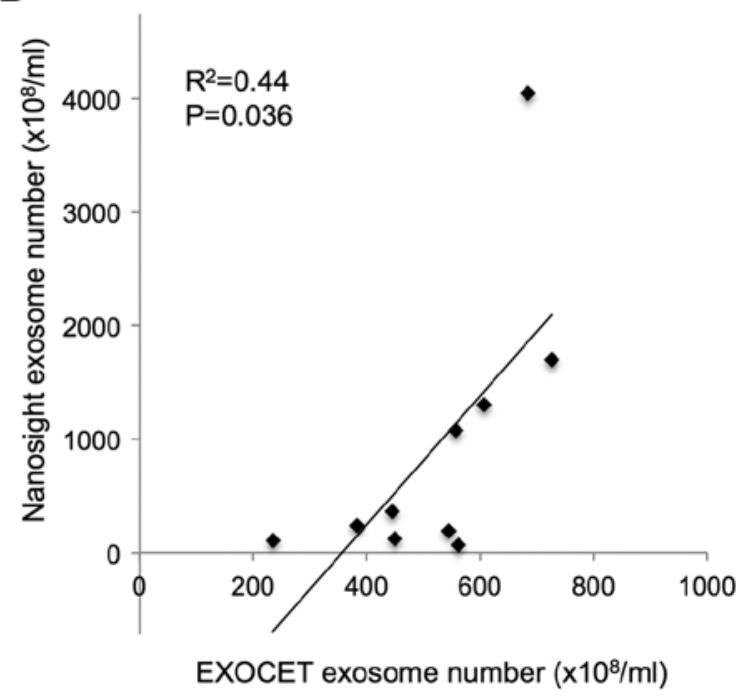

Figure 3. (A) The quantification of plasma exosomes isolated from 50, 100 and $200 \mu 1$ of plasma from a healthy control. The levels of exosomes isolated were dose-dependent $\left(\mathrm{R}^{2}=0.99 ; \mathrm{P}=0.044\right)$. (B) The correlation between exosome measured with AChE activity and nanoparticle tracking analysis. There was a positive correlation between the two quantification methods $\left(\mathrm{R}^{2}=0.43 ; \mathrm{P}=0.036\right)$.

A

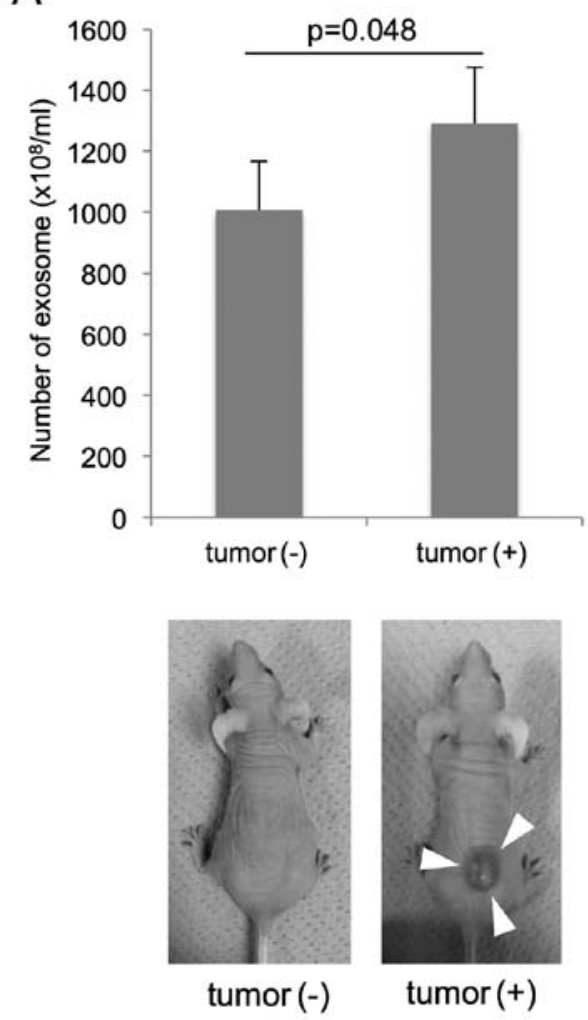

$\mathrm{B}$

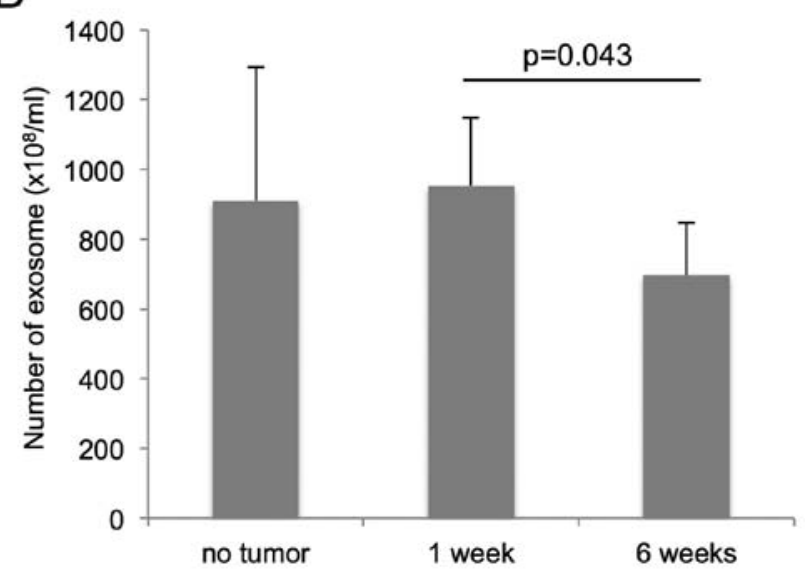

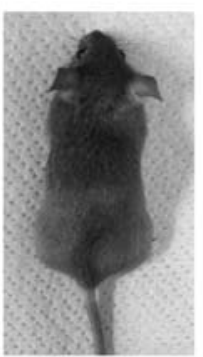

no tumor

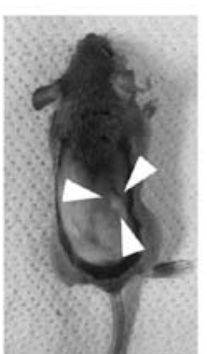

1 week

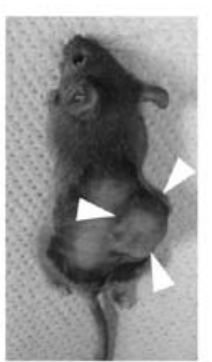

6 weeks

Figure 4. The plasma exosome quantification was assessed in murine models. (A) The group of nude mice (BALB/c Slc-nu-nu) with subcutaneous tumor composed of TE2-CD63-GFP (tumor volume, 1042 $\pm 293 \mathrm{~mm}^{3}$ ) had higher amount of plasma exosome $\left(1290 \pm 186 \times 10^{8} / \mathrm{ml}\right)$ than the group of mice without tumor $\left(1007 \pm 162 \times 10^{8} / \mathrm{ml} ; \mathrm{P}=0.048\right.$; t-test). (B) The exosome numbers of $\mathrm{C} 3 \mathrm{H} / \mathrm{He}$ mouse plasma were assessed 1 or 6 weeks after tumor implantation, and the exosome number of no tumor-bearing $\mathrm{C} 3 \mathrm{H} / \mathrm{He}$ mouse plasma was also assessed. The group with advanced cancer $(6 \mathrm{weeks}$ after implantation, tumor volume, $\left.2712 \pm 1339 \mathrm{~mm}^{3}\right)$ had lower exosome level $\left(695 \pm 170 \times 10^{8} / \mathrm{ml}\right)$ than that in the group with early cancer $\left(1\right.$ week after injection, tumor volume $\left.1.2 \pm 1.2 \mathrm{~mm}{ }^{3}\right)$ $\left(979 \pm 194 \times 10^{8} / \mathrm{ml} ; \mathrm{P}=0.043\right.$; t-test $)$.

There was no statistical difference between the clinical stages $(\mathrm{P}=0.68$; ANOVA).
A low exosome amount predicts a poor prognosis in ESCC patients. To determine the correlation between the plasma 
Table I. Clinical features of patients with esophageal squamous cell carcinoma $(n=66)$.

Clinicopathological

characteristics

\begin{tabular}{lc}
\hline Mean age \pm SD & $69.0 \pm 9.3$ \\
Gender & \\
Male & 57 \\
Female & 9 \\
Clinical T factor & \\
T1 & 20 \\
T2 & 5 \\
T3 & 21 \\
T4 & 20
\end{tabular}

Clinical $\mathrm{N}$ factor

$\begin{array}{ll}\text { N0 } & 19 \\ \text { N1 } & 12 \\ \text { N2 } & 20 \\ \text { N3 } & 15\end{array}$

Clinical $\mathrm{M}$ factor

M0

62

M1

4

Stage (UICC 7th)

I

II

18

4

III

40

IV

Treatment procedure

ESD 11

Surgery $\quad 22$

Non-surgical 25

CRT 18

CT $\quad 5$

RT 2

Palliative

UICC, International Union Against Cancer; ESD, endoscopic submucosal dissection; CRT, chemoradiotherapy; CT, computed tomography; RT, radiotherapy.

exosome amount and the prognosis of ESCC patients, an analysis of the overall survival was performed. The Kaplan-Meier approach, with a statistical analysis using the log-rank test, was performed for various clinicopathological factors, as presented in Table II. Regarding the exosome level, a cut-off value was set as $600 \times 10^{8} / \mathrm{ml}$.

The log-rank test showed that there was significant difference in the tumor depth, lymph node status, distant metastasis, clinical stage, the NLR and exosome number $(\mathrm{P}=0.011$, $\mathrm{P}=0.008, \mathrm{P}=0.002, \mathrm{P}=0.009, \mathrm{P}=0.009$ and $\mathrm{P}=0.044$, respectively), but age, gender, the serum level of SCC-Ag, CEA, and CYFRA and the GPS did not significantly affect the survival

Table II. Univariate analyses of the survival $(n=66)$.

\begin{tabular}{|c|c|c|c|c|}
\hline Variables & Categories & $\begin{array}{c}\text { No. of } \\
\text { cases }\end{array}$ & $\begin{array}{l}\text { 3-year } \\
\text { survival } \\
\text { rate }(\%)\end{array}$ & P-value \\
\hline \multirow[t]{2}{*}{ Age (years) } & $<65$ & 21 & 47.6 & \multirow[t]{2}{*}{0.357} \\
\hline & $\geq 65$ & 45 & 63.9 & \\
\hline \multirow[t]{2}{*}{ Gender } & Male & 57 & 57.1 & \multirow[t]{2}{*}{0.410} \\
\hline & Female & 9 & 74.1 & \\
\hline \multirow[t]{2}{*}{ Tumor depth } & $\mathrm{T} 1, \mathrm{~T} 2$ & 25 & 75.0 & \multirow[t]{2}{*}{0.011} \\
\hline & $\mathrm{T} 3, \mathrm{~T} 4$ & 41 & 48.2 & \\
\hline \multirow[t]{2}{*}{ Lymph node status } & Negative & 19 & 85.7 & \multirow[t]{2}{*}{0.008} \\
\hline & Positive & 47 & 46.6 & \\
\hline \multirow[t]{2}{*}{ Metastasis status } & Negative & 64 & 59.5 & \multirow[t]{2}{*}{0.002} \\
\hline & Positive & 4 & N/A & \\
\hline \multirow[t]{2}{*}{ Stage } & $\mathrm{I}, \mathrm{II}$ & 21 & 81.3 & \multirow[t]{2}{*}{0.009} \\
\hline & III,IV & 45 & 47.2 & \\
\hline \multirow[t]{2}{*}{ NLR } & $<3.7$ & 49 & 67.2 & \multirow[t]{2}{*}{0.001} \\
\hline & $\geq 3.7$ & 17 & 33.7 & \\
\hline \multirow[t]{2}{*}{ GPS } & 0 & 55 & 63.1 & \multirow[t]{2}{*}{0.164} \\
\hline & 1,2 & 11 & 37.5 & \\
\hline \multirow[t]{2}{*}{ Exosome } & High & 24 & 79.2 & \multirow[t]{2}{*}{0.044} \\
\hline & Low & 42 & 47.2 & \\
\hline
\end{tabular}

NLR, the neutrophil to lymphocyte ratio; GPS, Glasgow Prognostic Score; N/A, not available.

Table III. Multivariate analyses of the survival $(n=66)$.

\begin{tabular}{lccc}
\hline Categories & Odds ratio & $95 \%$ CI & P-value \\
\hline Stage III,IV & 4.85 & $1.62-21.01$ & 0.004 \\
NLR $\geq 3.7$ & 4.10 & $1.49-11.12$ & 0.007 \\
Low exosome & 3.15 & $1.11-11.41$ & 0.030 \\
\hline
\end{tabular}

CI, confidence interval; NLR, the neutrophil to lymphocyte ratio.

$(\mathrm{P}=0.357, \mathrm{P}=0.410, \mathrm{P}=0.225, \mathrm{P}=0.306, \mathrm{P}=0.333$ and $\mathrm{P}=0.164$, respectively). The 3-year overall survival rate in patients with high plasma exosome amounts was $79.2 \%$, whereas that of the patients with lower plasma exosome amounts was $47.2 \%$ (Fig. 6).

We next analyzed the importance of various factors that may be able to predict a poor prognosis for the survival. According to the univariate analysis, the clinical stage, the NLR and the exosome number were selected. We subsequently performed a multivariate analysis using a Cox proportional hazards regression analysis, and a lower exosome number in the plasma was found to be an independent risk factor for a poor survival with a hazard ratio of 3.152 (95\% confidence interval, 1.107-11.416; $\mathrm{P}=0.03$; Table III). 


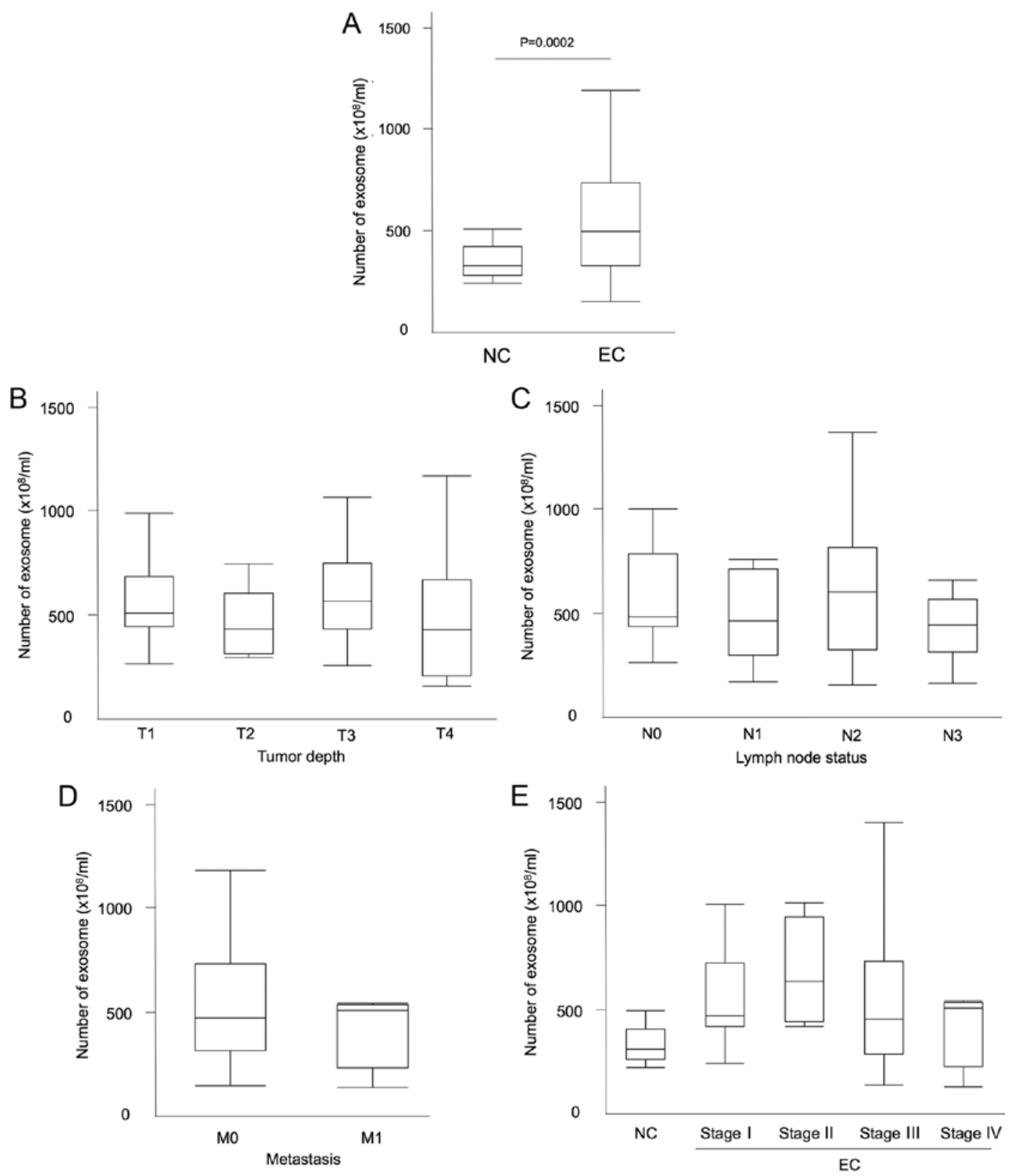

Figure 5. (A) The amount of exosomes extracted from patients with or without ESCC. The levels of exosomes from cancer patients were higher than that of patients without cancer ( $\mathrm{P}=0.0002$; Mann-Whitney U test). (B-E) The relationship between the characteristics of cancer and the amount of plasma exosomes: (B) tumor depth; (C) lymph node metastasis; (D) distant organ metastasis; and (E) clinical stage.

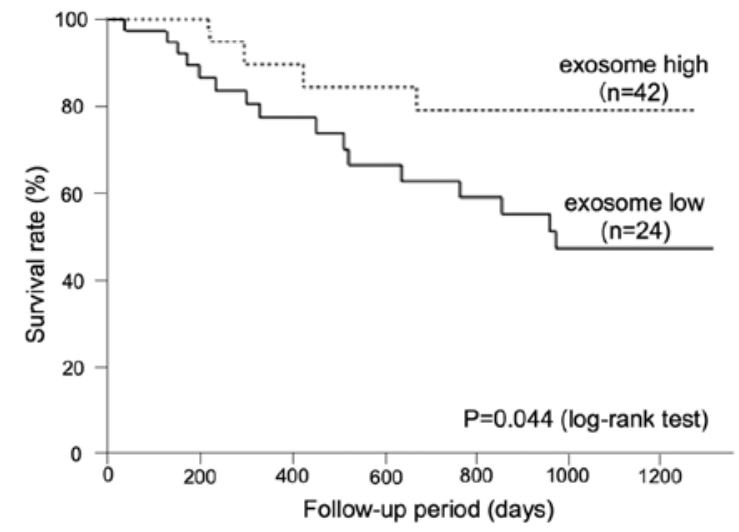

Figure 6. Kaplan-Meier survival curves according to the amount of exosomes in the plasma. The overall survival of the high exosome group $(n=42)$ was longer than that of the low exosome group $(\mathrm{n}=24)(\mathrm{P}=0.044$, log-rank test).

\section{Discussion}

Exosome analyses have been previously performed in cancer research. The previous studies mainly concerned the contents of exosomes, such as proteins or microRNAs. Numerous types of proteins and microRNAs have been reported to be useful as potential biomarkers, particularly miR-21 for ESCC (23), however, the origin of exosomes remains unclear and is difficult to discriminate. Although cancer-derived exosomes were considered to be released outside the tumor and circulate throughout the whole body (24), only a few studies have confirmed the exosome behavior in vivo. In the present study, cancer-derived exosomes were labeled by transfection with a CD63-GFP expression vector, and the circulation of ESCC tumor-derived exosomes in the 
blood flow was confirmed using mouse models as previously reported (25). Notably, a recent study reported that tumorderived exosomes may integrate into specific organs and affect organotropic metastasis (26).

Various studies confirmed that the number of exosomes or extracellular vesicles (EVs) in the peripheral blood are useful as a biomarker (27-29). The quantification of EVs has not yet been standardized. Therefore, in the present study, we quantified the exosome number according to the AChE activity, which is known to be rich in exosomes. Although quite a few proteins outside the exosome can be contaminated in the isolated exosome, our data showed there was no correlation between the quantified exosome number and the protein, included total protein, albumin and C-reactive protein. Although the AChE inhibitors, used for Alzheimer's disease, may influence the value, the patients did not take these medicines in the present study. The number of exosomes quantified by AChE activity was correlated with the number quantified by nanoparticle tracking analysis, and the plasma exosome number of non-malignant patients existed within a certain range. Furthermore, this procedure takes $\sim 1 \mathrm{~h}$ for exosome isolation and quantification, and needs only $100 \mu 1$ of plasma samples, thus, it is reasonable to quantify the exosomes according to the AChE activity.

Our data, including clinical analysis and in vivo mouse model analysis, indicated that tumor-derived exosomes can circulate in the blood and the plasma exosome amount of cancer patients was significantly higher than that of patients without cancer, however, the amount of plasma exosomes was not increased according to the tumor progression, such as lymph node metastasis or distant organ metastasis. Thus, we thought the majority of plasma exosomes were host derived or the amount of exosome released from the tumor decreased as the tumor grows.

Concerning host factors, a biochemical examination of the blood identify potential relationships with the exosome amount, however, there were no significant correlations. Immune cells including $\mathrm{T}$ cells and dendritic cells were thought to release exosomes (30), and exosomes also regulate the immune system (31). Therefore, we assessed the correlation between the exosome quantity and the NLR or the GPS. The NLR and exosome number are both independent prognostic factors, however, there was no correlation between these factors. A further assessment is necessary concerning the relationship between tumor-specific immune responses or immune evasion and the exosome level.

Whether the release of exosomes from the tumor changes as the tumor progresses was not revealed, however, some studies have indicated that the state of hypoxia enhances exosome release from the tumor (32), as well as a low $\mathrm{pH}(33,34)$. According to this theory, it may be reasonable that cancer-derived exosomes change or decrease when the tumor becomes far advanced and rich in vascular formation.

Taken together, although the precise factors remain unknown, it is possible that the exosome quantity reflects the state of cancer-specific immune responses or the tumor microenvironment and may predict the prognosis.

In conclusion, tumor-derived exosomes can be detected in the blood from the plasma in our established mouse model. The exosome quantity in the patient plasma did not correlate with the respective tumor progression in each ESCC patient, however, the amount of exosomes in the plasma, as measured using the AChE activity, was an independent prognostic factor for ESCC patients.

\section{Acknowledgements}

The present study was supported by a Grant-in-Aid for Scientific Research (grant nos. 15K19872 and 26670597) from the Japan Society for the Promotion of Science.

\section{References}

1. Global Burden of Disease Cancer Collaboration; Fitzmaurice C, Dicker D, Pain A, Hamavid H, Moradi-Lakeh M, MacIntyre MF, Allen C, Hansen G, Woodbrook R, Wolfe C, et al; The Global Burden of Cancer 2013. JAMA Oncol 1: 505-527, 2015.

2. Siegel RL, Miller KD and Jemal A: Cancer statistics, 2015. CA Cancer J Clin 65: 5-29, 2015.

3. Pennathur A, Gibson MK, Jobe BA and Luketich JD: Oesophageal carcinoma. Lancet 381: 400-412, 2013.

4. Tachimori Y, Ozawa S, Numasaki H, Fujishiro M, Matsubara H, Oyama T, Shinoda M, Toh Y, Udagawa H and Uno T; The Registration Committee for Esophageal Cancer of the Japan Esophageal Society: Comprehensive Registry of Esophageal Cancer in Japan, 2008. Esophagus 12: 130-157, 2015.

5. Akutsu Y, Uesato M, Shuto K, Kono T, Hoshino I, Horibe D, Sazuka T, Takeshita N, Maruyama T, Isozaki Y, et al: The overall prevalence of metastasis in $\mathrm{T} 1$ esophageal squamous cell carcinoma: A retrospective analysis of 295 patients. Ann Surg 257: 1032-1038, 2013.

6. Denzer K, Kleijmeer MJ, Heijnen HF, Stoorvogel W and Geuze HJ: Exosome: From internal vesicle of the multivesicular body to intercellular signaling device. J Cell Sci 113: 3365-3374, 2000.

7. van den Boorn JG, Dassler J, Coch C, Schlee M and Hartmann G: Exosomes as nucleic acid nanocarriers. Adv Drug Deliv Rev 65: 331-335, 2013.

8. Takeshita N, Hoshino I, Mori M, Akutsu Y, Hanari N, Yoneyama Y, Ikeda N, Isozaki Y, Maruyama T, Akanuma N, et al: Serum microRNA expression profile: miR-1246 as a novel diagnostic and prognostic biomarker for oesophageal squamous cell carcinoma. Br J Cancer 108: 644-652, 2013.

9. Skog J, Würdinger T, van Rijn S, Meijer DH, Gainche L, Sena-Esteves M, Curry WT Jr, Carter BS, Krichevsky AM and Breakefield XO: Glioblastoma microvesicles transport RNA and proteins that promote tumour growth and provide diagnostic biomarkers. Nat Cell Biol 10: 1470-1476, 2008.

10. Chen WX, Liu XM, Lv MM, Chen L, Zhao JH, Zhong SL, Ji MH, $\mathrm{Hu} \mathrm{Q}$, Luo Z, Wu JZ, et al: Exosomes from drug-resistant breast cancer cells transmit chemoresistance by a horizontal transfer of microRNAs. PLoS One 9: e95240, 2014.

11. Ichim TE, Zhong Z, Kaushal S, Zheng X, Ren X, Hao X, Joyce JA, Hanley HH, Riordan NH, Koropatnick J, et al: Exosomes as a tumor immune escape mechanism: Possible therapeutic implications. J Transl Med 6: 37, 2008.

12. Lundholm M, Schröder M, Nagaeva O, Baranov V, Widmark A, Mincheva-Nilsson L and Wikström P: Prostate tumor-derived exosomes down-regulate NKG2D expression on natural killer cells and $\mathrm{CD}^{+} \mathrm{T}$ cells: Mechanism of immune evasion. PLoS One 9: e108925, 2014.

13. Hu Y, Yan C, Mu L, Huang K, Li X, Tao D, Wu Y and Qin J: Fibroblast-derived exosomes contribute to chemoresistance through priming cancer stem cells in colorectal cancer. PLoS One 10: $\mathrm{e} 0125625,2015$.

14. Ono M, Kosaka N, Tominaga N, Yoshioka Y, Takeshita F, Takahashi RU, Yoshida M, Tsuda H, Tamura K and Ochiya T: Exosomes from bone marrow mesenchymal stem cells contain a microRNA that promotes dormancy in metastatic breast cancer cells. Sci Signal 7: ra63, 2014.

15. Walker ND, Patel J, Munoz JL, Hu M, Guiro K, Sinha G, et al: The bone marrow niche in support of breast cancer dormancy. Cancer Lett: Nov 3, 2015 (Epub ahead of print). pii: S0304-3835(15)00664-3. doi: 10.1016/j.canlet.2015.10.033. 
16. An T, Qin S, Xu Y, Tang Y, Huang Y, Situ B, Inal JM and Zheng L: Exosomes serve as tumour markers for personalized diagnostics owing to their important role in cancer metastasis. J Extracell Vesicles 4: 275224, 2015.

17. Savina A, Vidal M and Colombo MI: The exosome pathway in K562 cells is regulated by Rab11. J Cell Sci 115: 2505-2515, 2002.

18. Gupta S and Knowlton AA: HSP60 trafficking in adult cardiac myocytes: Role of the exosomal pathway. Am J Physiol Heart Circ Physiol 292: H3052-H3056, 2007.

19. Usui A, Hoshino I, Akutsu Y, Sakata H, Nishimori T, Murakami K, Kano M, Shuto K and Matsubara H: The molecular role of Fra-1 and its prognostic significance in human esophageal squamous cell carcinoma. Cancer 118: 3387-3396, 2012.

20. Akanuma N, Hoshino I, Akutsu Y, Murakami K, Isozaki Y, Maruyama T, Yusup G, Qin W, Toyozumi T, Takahashi M, et al: MicroRNA-133a regulates the mRNAs of two invadopodiarelated proteins, FSCN1 and MMP14, in esophageal cancer. Br J Cancer 110: 189-198, 2014.

21. Yodying H, Matsuda A, Miyashita M, Matsumoto S, Sakurazawa N and Uchida E: Prognostic significance of neutrophil-to-lymphocyte ratio and platelet-to-lymphocyte ratio in oncologic outcomes of esophageal cancer: A systematic review and meta-analysis. Ann Surg Oncol 23: 646-654, 2016.

22. McMillan DC: The systemic inflammation-based Glasgow Prognostic Score: A decade of experience in patients with cancer. Cancer Treat Rev 39: 534-540, 2013.

23. Tanaka Y, Kamohara H, Kinoshita K, Kurashige J, Ishimoto T, Iwatsuki M, Watanabe M and Baba H: Clinical impact of serum exosomal microRNA-21 as a clinical biomarker in human esophageal squamous cell carcinoma. Cancer 119: 1159-1167, 2013.

24. Yoshioka Y, Kosaka N, Konishi Y, Ohta H, Okamoto H, Sonoda $\mathrm{H}$, Nonaka $\mathrm{R}$, Yamamoto $\mathrm{H}$, Ishii $\mathrm{H}$, Mori $\mathrm{M}$, et al: Ultra-sensitive liquid biopsy of circulating extracellular vesicles using ExoScreen. Nat Commun 5: 3591, 2014.

25. Suetsugu A, Honma K, Saji S, Moriwaki H, Ochiya T and Hoffman RM: Imaging exosome transfer from breast cancer cells to stroma at metastatic sites in orthotopic nude-mouse models. Adv Drug Deliv Rev 65: 383-390, 2013.
26. Hoshino A, Costa-Silva B, Shen TL, Rodrigues G, Hashimoto A, Tesic Mark M, Molina H, Kohsaka S, Di Giannatale A, Ceder S, et al: Tumour exosome integrins determine organotropic metastasis. Nature 527: 329-335, 2015.

27. Fleitas T, Martínez-Sales V, Vila V, Reganon E, Mesado D, Martín M, Gómez-Codina J, Montalar J and Reynés G: Circulating endothelial cells and microparticles as prognostic markers in advanced non-small cell lung cancer. PLoS One 7: e47365, 2012

28. Tavoosidana G, Ronquist G, Darmanis S, Yan J, Carlsson L, Wu D, Conze T, Ek P, Semjonow A, Eltze E, et al: Multiple recognition assay reveals prostasomes as promising plasma biomarkers for prostate cancer. Proc Natl Acad Sci USA 108: 8809-8814, 2011

29. Silva J, Garcia V, Rodriguez M, Compte M, Cisneros E, Veguillas P, Garcia JM, Dominguez G, Campos-Martin Y, Cuevas J, et al: Analysis of exosome release and its prognostic value in human colorectal cancer. Genes Chromosomes Cancer 51: 409-418, 2012

30. Quah B and O'Neill HC: Review: The application of dendritic cell-derived exosomes in tumour immunotherapy. Cancer Biother Radiopharm 15: 185-194, 2000.

31. Robbins PD and Morelli AE: Regulation of immune responses by extracellular vesicles. Nat Rev Immunol 14: 195-208, 2014.

32. King HW, Michael MZ and Gleadle JM: Hypoxic enhancement of exosome release by breast cancer cells. BMC Cancer 12: 421, 2012.

33. Parolini I, Federici C, Raggi C, Lugini L, Palleschi S, De Milito A, Coscia C, Iessi E, Logozzi M, Molinari A, et al: Microenvironmental $\mathrm{pH}$ is a key factor for exosome traffic in tumor cells. J Biol Chem 284: 34211-34222, 2009.

34. Ban JJ, Lee M, Im W and Kim M: Low $\mathrm{pH}$ increases the yield of exosome isolation. Biochem Biophys Res Commun 461: 76-79, 2015. 